\title{
How to Resolve Comte's Challenge: The Answer of Cognitive Neuroscience and the Neo-Aristotelian Alternative
}

\author{
Harry Smit ${ }^{1}$
}

Received: 6 May 2020 /Revised: 29 October 2020 / Accepted: 5 November 2020 /

Published online: 23 November 2020

(C) The Author(s) 2020

\begin{abstract}
Comte argued against the Cartesian conception of the mind that the thinker cannot simultaneously think or perceive and observe itself so doing. Based on insights from cognitive neuroscience, Dehaene has recently given a contemporary answer to Comte's challenge. He has extended some ideas of Helmholtz on unconscious inferences and argued that we can resolve Comte's problem by reformulating it in terms of the brain. Since the brain consists of different parts having different functions, it is possible that some parts are involved in observing (they unconsciously process information) while other parts integrate the received information resulting in conscious experiences to which we have access. Dehaene's answer is criticized and the alternative neoAristotelian resolution of Comte's challenge is discussed. Explanations of blindsight are used to illustrate the differences between the two responses to Comte's challenge.
\end{abstract}

Keywords Blindsight $\cdot$ Cognitive neuroscience $\cdot$ Comte's challenge $\cdot$ Conceptual resolution $\cdot$ Perception $\cdot$ Sensation

\section{Introduction}

We are inclined to think that, when we have a pain (or an emotion, thought, and so on), others cannot have the experience we have and, hence, cannot really know what it is like. Moreover, it seems that we know this with absolute certainty, for when I have a pain, I am aware of the pain I have. I feel my pain, and if I sincerely say that I have a pain nobody can gainsay me (I enjoy a form of authority).

Harry Smit

h.smit@maastrichtuniversity.nl

1 Department of Cognitive Neuroscience, Faculty of Psychology and Neuroscience, Maastricht University, P.O. Box 616, 6200 MDMaastricht, The Netherlands 
Ever since these Cartesian ideas were advanced about our own experiences and how we know them they have been criticized. A well-known and important challenge came from Comte (summarized in James 1950, vol. 1, pp. 188-190). He (Cours de Philosophie Positive, Vol. 1, pp. 34-38) argued that 'this pretended contemplation of the mind is pure illusion' on the ground that the mind cannot simultaneously perceive, feel, or think, and observe itself so doing. 'The thinker cannot divide himself into two, of whom one reasons whilst the other observes him reason'. Mill (1961 [1865], p. 64) responded to Comte's challenge by insisting that 'a fact may be studied through the medium of memory, not at the very moment of our perceiving it ...'. According to Mill, we know how things are subjectively with us, but only a few seconds after the event has occurred. There is according to Mill no difference between perceptions and actions. 'We reflect on what we have been doing when the act is past, but when its impression in the memory is still fresh'. James (1950, vol. 1, p. 90) agreed with Mill and argued that 'no subjective state, whilst present, is its own object, its object is always something else'. Memory is according to James relevant for understanding why we can perceive something and reflect on what we perceive. But, James added, memory is fallible, raising the possibility that the thinker, in contrast to what Descartes argued, is not absolutely certain about what he or she is aware of. Is the thinker absolutely certain or does he or she occasionally make mistakes? And if the thinker makes mistakes while introspecting, how can we explain these mistakes?

In this paper we discuss contemporary answers to the challenge of Comte, namely the answer of cognitive neuroscience exemplified by Dehaene and the neo-Aristotelian alternative. Dehaene (2014, p. 25) argues that we have to reformulate Comte's challenge in terms of the brain. According to his version of Comte's challenge the essential question is whether the brain can simultaneously think, will or perceive and observe itself thinking, willing or perceiving. Dehaene's answer is that the brain consists of different parts, structures or networks, and these have different functions. And because they have different functions, it is possible that some parts are involved in observing while other parts are involved in integrating this information leading to experiences to which we have conscious access. In the terminology of cognitive neuroscience: the prefrontal cortex is the structure coding the conscious or thinking 'I' or self, while other parts are involved in 'unconsciously processing information' and provide the prefrontal cortex (in which the 'I' or self is seated) with raw data. We shall discuss why the solution Dehaene suggests does not resolve Comte's problem and elaborate the neo-Aristotelian alternative.

\section{Methodological Limitations}

Dehaene is a representative of a growing group of cognitive neuroscientists who believe that the essence of the mental is not a thinking substance separate from the body (as Descartes thought), but a state of the cortex. He opposes, like neo-Aristotelians (or neoDarwinians, for Darwin returned to Aristotelian ideas and extended them with evolutionary theory; see Darwin 1968 [1859], chapter 6; Kenny 1988; Hacker 2007, chapter 6), Descartes's dualism and replaces it by a form of monism. Yet in contrast to neoAristotelians, he does not argue that it is the organism as a whole (or the human being) that has emotions, thinks or is conscious, but its brain. It is the brain that codes thought and consciousness. And while neo-Aristotelian scientists study the development of the mind 
by investigating how human capacities evolve (i.e. the development of visible or audible behavioural and linguistic expressions of emotions, thoughts, et cetera), Dehaene believes that, for understanding the development of the mind, we have to investigate the development of thought or consciousness as products of the brain. We can according to him study how introspective reports of subjects (of what they perceive, think, will, and so forth) inductively correlate with cortical states (i.e. 'activities' of brain areas) with the aid of techniques such as fMRI and ERP (Dehaene 2014, chapter 1). According to him, the core term for understanding the mind is conscious access. Dehaene follows here Descartes's characterization of consciousness: it is the awareness of thoughts or experiences within us. Descartes redefined thought to incorporate 'everything which we are conscious of as happening within us, insofar as we are consciousness of it' (Principles of Philosophy, I, 9). Accordingly, perceptual experience, imagination, cogitation, affection and volition constitute the domain of consciousness. Dehaene, following Helmholtz, adds that a large part of information 'processed by the brain' is processed unconsciously. Yet this information may become conscious when it is further integrated in 'the workspace of the mind' (we have then conscious access to this information). During fMRI-experiments we can ask subjects to report when they become conscious of something and can use these reports for detecting, what Dehaene calls, signatures of consciousness in their cortex. These signatures are changes in brain activity measured with fMRI. The results of these studies enable us to give empirical answers to the question how consciousness is encoded in brain processes and when it evolves in children, since the signatures of cortical activity correlate with the mental states children are in. Thus Dehaene suggests that cognitive neuroscience is capable of answering Comte's challenge: with the aid of empirical methods we can study when consciousness arises in certain cortical parts of the brain as the result of integrating information provided by other parts that unconsciously process information. We shall argue that Dehaene's answer to Comte's challenge is for logical or conceptual reasons incoherent.

We start our critical discussion by mentioning some methodological limitations linked to the methods used by Dehaene and other (developmental) cognitive neuroscientists (see also Nachev and Hacker 2010). First, current techniques of cognitive neuroscience enable us to study the development (of activities in) a child's brain in a rough way, but they are not capable of differentiating between - say- changes in activities of different structures like the subplate and the cortical plate. Dehaene is for this reason silent on the transient role of the subplate in the development of the brain during the first year of child development (discussed in Hadders-Algra 2018a; Kostović et al. 2019). That is an omission, for it is according to neo-Aristotelians essential to notice that infants begin to act at will after the neonatal transition (Hadders-Algra 2018b; Shultz et al. 2018) when early reactions and instinctual behaviours, modulated by the subplate, give way to volitional behaviour. At about 3 months post-term the permanent circuitries in the primary motor, somatosensory and visual cortices (begin to) replace the role of the subplate. The subplate gradually disappears in the remainder of the first year as the result of apoptosis. Secondly, Dehaene studies changes in activities of brain areas with techniques from physics, but these do not tell us how the brain develops. For example fMRI is a technique resulting in pictures of brain activity. We explain the technique in a simplified way. It is based on the observation that increased activity in a certain brain area requires extra oxygen. Oxygen is transported by haemoglobin (a metal containing protein that is part of red blood cells) 
through blood vessels to active neurons. The iron atom of haemoglobin molecules is either an (unbonded) ion or bonded to oxygen. Deoxygenated haemoglobin (the ionstate of the iron atom) is more magnetic than oxygenated haemoglobin. Deoxygenated haemoglobin therefore interferes more with magnetization than oxygenated haemoglobin. By using a strong magnetic field, we can detect this difference and use it to create with the aid of computer programs pictures giving us an impression of oxygen-transport and, hence, of the activity of a cortical area. The point to notice is that BOLD (blood oxygen level dependency) signals on a scanner screen tell us something about the activity of neurons in a certain area in the here and now, but, in contrast to biological markers or signatures of for example cell migration, differentiation or apoptosis (e.g. markers of gene activity or their epigenetic regulation), do not tell us anything about how brain structures and networks develop. We mention two examples illustrating how cellular processes facilitate the development of behaviour at the level of the organism (see further Kirschner and Gerhart 2005). During the early stages of prenatal development the hand looks like a paddle. The fingers are created by apoptosis (cell death) of the cells in between the developing fingers. Fingers later get a role in the grasping reaction of babies. Hence apoptosis is a cellular process facilitating the development of the grasping reaction displayed by the baby (as a whole). Long term potentiation and depression (LTP and LTD) are processes occurring at the level of the cell and are a prerequisite or causal condition of forms of learning and memory, but it is the organism as a whole that learns and remembers something. LTP and LTD facilitate the development of mental powers, but cells do not learn and remember what organisms learn and remember.

Thirdly, because Dehaene starts with the Cartesian presupposition that consciousness is the mark of the mind, his main question concerning the development of the mind is when cortical areas (in which the conscious self is thought to be seated) of infant brains become active. He asks whether cortical activities in baby brains are similar to those found in the adult brain. Hence his ideas about the development of the baby brain are constructed by taking the adult brain as a template. For example Dehaene and his co-workers have presented empirical evidence showing that the brains of 2-3 months old infants and adults show during an fMRI-experiment similar cortical activation as a response to being exposed to faces or sequences of sounds, although these responses are in infants up to four times slower than in adults (his explanation of this difference is that, in infants, the axons involved still have to be insulated by myelin sheaths). Because of these and other similarities, Dehaene (2014, p. 243) concludes that 'we can assume that babies already enjoy conscious vision, although they cannot yet report it by speaking aloud'. The infant's mind is according to him a conscious mind, but because their cortex responds slowly, we have to think of it as a foggy, dawdling mind.

Given these results obtained with the methods of cognitive neuroscience, Dehaene expects that brain networks involved in consciousness to be already present and active at birth. He hypothesizes that consciousness emerges immediately after babies are born. Moreover, he surmises that foetuses might have been to a certain extent conscious as well, but argues that during pregnancy the baby is, in utero, probably sedated because of certain chemical substances (such as pregnanolone) to which they are exposed. Notice that these ideas on the infant mind before the neonatal transition are not based on any empirical data obtained with the methods of developmental cognitive 
neuroscience, i.e. a fMRI scan of a baby brain while babies are engaged in a cogitative exercise. When Dehaene and co-workers study cortical activity of babies younger than 2 months in a scanner, they study them when they are asleep, and when they collect data about the brain activity of 2-3 months old babies, they measure responses to some simple stimuli (for infants cannot yet execute complex conative and cognitive tasks).

\section{Sensations and Perceptions}

In his resolution of Comte's challenge Dehaene distinguishes the conscious prefrontal cortex from other parts of the brain that unconsciously process information. He (2014, pp. 50-51), just as other cognitive neuroscientists, discusses his ideas about 'unconscious processing of information' as an elaboration of Helmholtz's ideas about 'unconscious inferences'. From Helmholtz Dehaene takes the distinction between sensation and perceptions, both being part of how the brain processes information. We shall discuss the Cartesian roots of this distinction and explain why it is incoherent and leads to unresolvable problems. These problems can be traced back to analogies first used by Galileo and Descartes (see Ben-Yami 2015; Hacker 1995).

Helmholtz (in Warren and Warren 1968, p. 82) argued that, when we perceive something, all we apprehend of the external world around us is brought to our consciousness by changes produced in our sensory organs by means of 'external impressions' (just as a seal is impressed upon a wax tablet). For example as the result of light-waves impinging upon our retinae, the resulting retinal impressions are transmitted to the cortex by nerves. In the brain these impressions become, or are transformed into, 'sensations'. These sensations are according to Helmholtz subsequently 'interpreted' or 'synthesized' by the unconscious mind (these unconscious 'processes' can also result in 'conscious perceptions', but that was not Helmholtz's main interest). Sensations are discussed by Helmholtz as data used by children to make unconscious, mental inferences.

It is true that physical stimuli (the absorption of photons by the protein rhodopsin and photopsin in the membranes of respectively rod and cone cells) cause, as the result of a cascade of biochemical processes, electrical discharges of cells that are transmitted as action potentials along nerves to the cortex. But, in contrast to what Helmholtz thought, an electric impulse cannot become a sensation. Appropriate electrical impulses are causal conditions for having a certain sensation, but are not transformed into a sensation (only in the fairy-tale is the frog transformed into a prince). Moreover, while we can have a headache (a stinging, throbbing, burning or nagging sensation felt in our head), we do not have and feel sensations of what we see (e.g. a colour) in our head or brain. Why, one can ask, did Helmholtz talk in the context of perceptions about sensations? He took this analogy from Galilei and Descartes. They used the analogy with the sensation pain (and with tactile perception, e.g. feeling with our fingers whether something is hot or cold, or smooth or rough) in order to clarify that what we perceive does not resemble something in the external world. Suppose that, while preparing dinner, I cut my finger with a knife. The sensation pain I subsequently have does not resemble anything in the knife, though the knife is the cause of my sensation. Helmholtz (following Galilei and Descartes) argued that perceptions do for similar reasons not resemble the causes of them (in Cohen and Elkana 1977, pp. 121-122). Yet 
the problem with the use of an analogy with the sensation pain is that, when we perceive a red rose in the garden, we do not have any sensation somewhere in our mind or brain (comparable to the sensation of a headache). We see the colour of an object (it is a property or quality of an object, not an object itself) in the external world, not in our mind, and we do not feel anything (while we feel a pain). To have a visual perception of a red rose is simply to see it. In other words: it is doubtful whether the use of the analogy with sensations makes any sense.

The second reason why the distinction between sensation and perception is incoherent is that Helmholtz treated sensations as the 'raw material'. He believed that perceptions arise from sensations when children learn to interpret sensations they have. In order to explain what is meant with 'interpreting', Helmholtz used an analogy with logical inferences: children learn to apprehend external objects by inference from sensations (in Warren and Warren 1968, p. 174). Not consciously, for it is according to him the unconscious mind that makes inferences. Hence sensations are combined or synthesized in the mind or brain as the result of unconscious inferences leading to perceptions (also called ideas or conceptions by Helmholtz) of objects. The resulting perceptions are conceived to be conclusions of unconscious inferences the premises of which are sensations. Perceptual judgments are according to Helmholtz generalizations (equally unconscious) about correlations between past sensations and objects perceived.

Let us first ask and answer a simple question: what is the difference between a valid inference and an invalid one? Recall that children learn inferences when they are taught inference forms or schemas with the aid of concrete examples (the technique of inferring). They also learn then possible invalid inferences. Take the following inference: 'Snow is white, therefore it is not black'. It will be clear that it is a valid inference. Suppose a child says 'Snow is white, therefore it is deep red', then a caregiver will correct him or her, for he or she made a false inference, although the premise is correct. Now suppose a child says: 'Lions are herbivores, therefore they graze', then we will also correct him or her: the inference is correct but the premise is false. The thing you have to notice is that Helmholtz never discussed the second possibility. There is a simple reason. In his discussion of unconscious inferences he presupposes that in unconscious inferences the premises are always true. For he believed that sensations, being premises of unconscious inferences, are always true (recall that sensations are the raw data which are interpreted by the child).

We can ask whether these alleged sensations can function as premises in inferences. The point to notice is that the premise of a logical inference is a sentence or proposition ('e.g. 'Snow is white' is a true premise and 'Snow is black' is a false premise). Logically, we cannot make inferences with a single word as a premise. Drawing a conclusion and making judgments also require the use of sentences or propositions. Based on perceptions (a child sees a red rose in the garden), the child, understanding the use of words ('flower', 'red', 'therefore', and so on), can draw conclusions by combining sentences according to an inference schema, e.g. 'The rose is red, therefore it is not white', and judgments, e.g. 'That there is a red rose in the garden' is a true judgment if there is a rose in the garden with this colour.

Sensations we have are not sentences. The problem is that, when we perceive something, there is no such thing as deriving a conclusion or a truth from a sensation (as if the sensation were a premise). As Ryle (2009) pointed out: sensations are not data 
providing us with information, while telling someone that there is a red rose in the garden is providing him or her with information ('data'). Why, one can ask, should we invoke the notion of an inference (based on a sensation) when we want to explain perception in the first place? For there is, in contrast to what Helmholtz believed, no sensation but also no inference involved when we perceive something.

\section{The Brain as the Organ of Thinking}

Cognitive neuroscientists have reformulated Helmholtz's ideas about unconscious inferences in terms of how a computer processes information. We should according to them think of the brain as a computer, as an information-processing system. However, they still adhere to the Cartesian conception of consciousness and the distinction between sensations (now conceived as representations) and conscious experiences. What Descartes called 'thoughts' is roughly coextensive with what they call 'experiences'. These experiences are now conceived as the upshot of 'informationprocessing computations' in the brain operating on sensory inputs (see e.g. Dehaene 2014; Dennett 1993; Tononi 2005). The computations result at first in non-conscious 'representations', but when information is further 'integrated' at higher levels (in the 'workspace of the mind'), they may result in conscious experiences. These are known by introspection, which is conceived as a form of 'meta-cognition' (it is assumed that there is a 'self-monitoring system' present in the brain that allegedly makes use of internal representations). The difference with Descartes is of course that they no longer believe that these processes occur in a separate substance, but in the brain. But can the brain be conceived as an organ that is engaged in thinking and has conscious experiences?

Let us first answer the question whether the brain is the organ of thought or conscious experiences, just as the stomach is the organ of digestion, the legs the organs of walking, or the mouth the organ of speaking. Do we think with our brain? It is true that we would not be able to engage in thinking if the brain does not function normally. But that does not show that the brain is the organ of thought with which we think. For if the brain does not function appropriately, we would also not be able to walk or talk, and that does not show that we walk or talk with our brain, for we walk with our legs and talk with our mouth, not with our brain. It shows that the brain is a prerequisite for many normal functions. Moreover, the brain does not do anything that can count as expressing or manifesting thought: the brain does not speak thoughtfully or stupidly, does not hold opinions, does not draw conclusions, and so on (BOLD signals on a scanner screen are not expressions of thought either). And while we use our eyes for seeing and our legs for walking, we cannot use our brain to engage in thinking, for it not an organ for a voluntary human function (the brain is not under our direct control). Since we cannot $d o$ anything with our stomach either, although it does something (it is the organ of digestion), we can ask whether the brain is the organ of thinking in the same way. Some cognitive neuroscientists have argued so (see e.g. Ginsburg and Jablonka, 2019, chapter 5, p. 151). Since there is an obvious difference, namely that we can observe how our stomach digests food (we observe how food is transformed into another substance as the result mechanical and chemical processes) but not how our brain engages in thinking, perceiving and so on (we only observe action potentials, 
neurotransmitters, and so on), they add that the latter are hidden (and unconscious). Yet this only mystifies issues, for no answer is given to the question of what these allegedly hidden processes and mechanisms are (neural processes or mechanisms are for sure not thinking processes or mechanisms). The normal activity of or processes in the stomach satisfy the criteria for digesting, but there is nothing a brain can do (or a neural activity or process) that can count as thinking or having conscious experiences.

Can conscious experiences be conceived as the upshot of 'information-processing computations' in the brain? Cognitive neuroscientists, just like Helmholtz, argue that conscious experiences arise in two steps. The computations result at first in nonconscious 'representations' that may result in conscious experiences when they are 'processed' by the brain. But this does not resolve problems, for the notion of representation is left unexplained. Cognitive neuroscientists like Dehaene believe that processed information becomes available as a representation when it catches and holds someone's attention. But increased firing of neurons (as the result of sensory input) does not represent what causes it, either in a pictorial or in a symbolic sense. The firings are indicative of something, but do not represent what they indicate, just as smoke indicates fire but does not represent it in the sense in which a painting or description of a fire represents it. Hence when we say that there is a 'neural correlate' between a perceived phenomenon and increased firing of neurons, it is ill-advised to say that it results in a mental representation.

We can conclude that conscious experiences do not arise in the brain, and that the brain is not the organ of conscious experiences in the same way as the stomach is the organ of digestion. Hacker (2019, chapter 10) has recently argued that cognitive neuroscientists can perhaps draw the analogy between thinking and digestion and physical activities in other sense, namely that the analogy concerns how we think and how we digest food or walk of talk. One can argue that there is an analogy between the soundness of digestion and the soundness of reasoning. Furthermore, we may think fast or slow just as we eat or move fast or slow; we engage in thinking with and without a purpose just as we move towards a goal or without one, and so forth. These analogies with physical activities can in concrete situations be further elaborated by referring, not to the brain or brain processes, but to what someone is doing and what he or she is saying in a given context, for there are for example behavioural criteria for fast and slow thinking. Furthermore, beating one's head is a criterion for racking one's brain (to think hard), and closing one's eyes for thinking better. But notice that these observable criteria of 'how we think' should not be confused with the claim of cognitive neuroscientists that thinking is a process going on in the brain resulting in thoughts or conscious experiences. We misconstrue then the analogy, for we attribute the concepts to the (whole) human being engaged in thinking, not to (processes in) the brain.

\section{There is no Foundation of Knowledge in Subjective Experiences}

We have seen that cognitive scientists like Dehaene adhere to the Cartesian conception of consciousness. Descartes redefined thought to incorporate everything we are conscious of. His redefinition of thought led to the idea that, when we see for example a tree, what we are immediately aware or conscious of is a private phenomenon (a subjective experience). While neo-Aristotelians argue that we can become and be 
conscious of something, Descartes and his followers argue that we have a subjective experience of something. Our ability to say what we see depends according to Descartes always upon our awareness of the content of our private experiences. This raises of course the question of how we become aware of what passes in our minds.

Descartes and his successors suggested that our awareness of the content of our experiences is a sort of perception (called apperception or introspection). We possess an interior perceptual faculty ensuring that we know what passes in our minds. There are two well-known reasons why this notion of consciousness as apperception is a misconception. First, there are no 'inner eyes' with which we can scrutinize the content of our experiences. We do not perceive experiences; we have them. Being aware of what we experience belongs to the category of capacity, not to the category of introspection. Second, attending to our subjective experiences is not like pointing to an object to which we attend. There are no 'inner fingers' with which we can point to experiences, and experiences are not entities populating an internal, psychological world to which we can refer.

There is a deeper reason why these Cartesian ideas about how we acquire knowledge of subjective experiences are misconceived. It misguidedly suggests that we learn the meaning of words such a 'tree' or 'red' by associating them with private experiences. The Cartesian conception leads to the misconception that elementary subjective experiences are the primary source of our knowledge of and communication about the world around us, and that our knowledge of objects and their properties in the external world is secondary to this knowledge of subjective experiences. We explain in this section why this idea is a misconception, and discuss in the next section why the Cartesian conception misconstrues the way children learn to communicate about what they perceive.

The main problem with the Cartesian conception is that learning words by associating them with subjective experiences is logically impossible, for it cannot provide users with rules or norms for the correct application of words. Suppose we present a child with a red object (e.g. a tomato) with the aim of teaching him or her the meaning of 'red'. According to the Cartesian conception, the child is then brought to the point of giving him- or herself the correct mental ostensive definition, for it presupposes that the content of a private, mental experience, to which the child attends, functions as an entity to which the child as it were inwardly points. The problem, we have seen, is that there are no inner eyes with which we can apperceive experiences and experiences are not entities populating an internal world. Consequently, there are no mind-dependent entities that can function as standards for the correct application of the word 'red'. Hence colour words cannot, for logical reasons, be defined by allegedly private, ostensive definitions. How, then, do we acquire the ability to use colour words in accord with rules or norms? An answer to this question requires an explanation of how ostensive definitions function as rules for the application of words.

Colour words are defined by referring to the colours in the objective, external world, not by referring to ideas (or visual images) in the subjective, internal world. Take the example of the colour red. Children learn (the conventional rules for) the use of the word 'red' when caregivers teach them the meaning of 'red' by pointing at for example a ripe tomato. If a parent points at a tomato and utters the sentence 'This is red', then he or she gives an ostensive definition (Baker and Hacker 2005, essay 5; see also Austin 1962). It can be paraphrased as 'This colour is red' or 'This colour is called red'. 
The tomato is then used as a sample (a standard of comparison) for explaining what red is, and can be used to determine whether other objects in the surroundings are red too. For they are correctly said to be red if they are the colour pointed at. The functioning of a colour sample as a standard is comparable to the role of the metre rule as a sample: saying that the length of a certain object is one metre recapitulates an explanation of what it is for something to be one metre long (namely to be that length).

It is important to see that the meaning of a word explained by an ostensive definition is not an object. When we use for example a ripe tomato to explain 'red', we do not connect a word to an object (as the Vienna Circle thought; see for example Feigl 1949), but use the tomato as a sample belonging to the means of representation. The tomato used as sample pro tempore belongs to what represents rather than to what is represented. The sample is not an entity 'outside language' which justifies the use of our colour words, but is used as an instrument of our language. And the ostensive definition does not, as it were, step outside language connecting language to reality. There is, in this sense, no foundation of our symbolism in reality. Once it is clear that samples belong to the representational method, not to what is represented, it is also clear that ostensive definitions, like verbal definitions, are movements within grammar. Consequently, grammar is autonomous: it is a free-floating network of concepts connected to each other through explanations, definitions, paraphrases, and so on.

For understanding that grammar is autonomous it is also important to see that ostensive definitions are not descriptions. When we utter for example the sentence 'This is red', we can and must clearly distinguish two possibilities. Either the sentence is used as description, e.g. 'This (rose) is red' (which can be true or can be false), or it is used as an ostensive definition (a rule or norm) which cannot be true or false but can be correctly or incorrectly used and applied. When we use 'This is red' as an ostensive definition, we do not describe anything but explain the meaning of 'red'. Descriptions, but not definitions, can be compared to what they are representations of. We can compare a description to what is describes, just as we can juxtapose a realistic pictorial representation (e.g. a drawing of person) with what it represents (we can compare it with what it represents for verisimilitude). Yet ostensive definitions are not representations but rules. When we explain the normativity of ostensive definition, there is no comparing involved, let alone the psychological acts of comparing and remembering (as the Vienna Circle thought; see for example Carnap 1961, par. 78). There is no such thing as juxtaposing a mental image of for example red to a current observation of an object, just as there is no such thing as judging whether a piece of string is a metre by trying to hold up a mental image of a metre string and juxtaposing it with the piece of string one is looking at. When we say that another object is red we do not mean that this is justified provided that the other object resembles or is similar to a private sample. To say of another object that it is that colour (while pointing at the sample) is to say that it is that colour (not that it is similar to the colour of the ostended object).

We can conclude that children understand the meaning of colour words when they are mastering the rules for the use of these words. Understanding these rules is a capacity. When children are capable of using words in accord with norms, this capacity is visible in what they do and say, just as using a metre rule correctly is visible in someone's behaviour. Understanding the rules for the use of colour words enables them to communicate about the colours they see. And if children understand our practice of using colour samples or a metre rule as a defining sample, they also learn to apprehend 
descriptions of coloured objects ('This rose is red') and the length of objects ('This stick is two metres long'). The linguistic capacities they learn are learnt extensions of their (innate) discriminatory capacities. They acquire on top the ability to respond to colours (which is, in Aristotelian terms, part of the sensitive psuchē) the ability to communicate about colours when they acquire the capacity to use colour words correctly (which is part of the rational psuchē). Yet children also learn to use expressions like 'This looks red' or 'I know there was a red rose because I have seen it'. How do they learn to use a perceptual vocabulary?

\section{How Children Acquire the Use of a Perceptual Vocabulary}

We have seen that it is logically impossible to learn the meaning of concepts by attending to private experiences. We have also seen that the self-predication of a perceptual verb ('I see a red rose in the garden') does not rest on observing one's own perception (for there is no such thing), but on perceiving what is in one's field of perception (we see with our eyes). Furthermore, it cannot be said that organs like eyes or the brain perceive or have 'visual experiences'. It is the sentient being (or animal as a whole) that perceives and has experiences. We shall now turn to question of how children learn to communicate about things with the aid of perceptual verbs.

When children start to play with objects and toys, give them to their caregivers, and so on, their caregivers teach them the meaning of words (by explanations involving pointing at objects). The point to notice is that learning the use of the names of objects and their properties (and descriptions) precedes he acquisition of perceptual verbs. Only if children understand the use of words such as 'tree', they can learn to say sentences such as 'I see a tree', for perceptual verbs are predicate-forming operators on nominals specifying an object of perception (but also on events and state of affairs perceived). Perceptual verbs are being mastered when children learn to ask and respond to questions such as: 'Can you see. ..?' or 'Did you hear. .. ?'. And when they learn to use these verbs by answering such questions, they also learn to answer the question 'How do you know?'. For example if a caregiver asks a girl: 'How do you know that Mummy is in the garden?', she can answer that she saw her there. Hence by engaging in these language games, they begin to understand that the exercise of the senses is properly cited as a source of knowledge. They then understand that when someone sees for example a red rose and says so, he or she introduces a report on public visibilia ('I see ...') or justifies such a report by citing what he or she saw. The conceptual point to notice is that children, by using (learning to use) a perceptual report, do not (learn to) justify the claim that things are thus or so because it offers a corroboration of a private psychological experience. The utterance specifies the sense-faculty by the use of which they came to know things to be so (what they say to be so). Hence by affixing the operator 'I see' to 'that things are so', the exercise of the senses is cited as a source of knowledge.

When they are mastering the use of perceptual verbs, they do not only learn that the senses are a source of knowledge, but also that observation claims are defeasible. These claims are not always right, for observation conditions are sometimes suboptimal, sense-organs are sometimes defective (temporarily or permanently), and the objects may look other than they are. When they make errors, their parents will correct these 
and will explain how children can correct errors: by looking again or by improving the observation conditions (moving closer, turning on the light). They then learn the use qualifying expressions such as 'This looks like ...', 'I think it is ...', or 'This appears to be ...'. They begin to understand that these operators are used to qualify observational sentences and are used when the employment of the senses and the cognitive faculty was not optimal. It enables them to understand error and illusion.

Summarizing: the (neo-Aristotelian) explanation of how children acquire the use of a simple and later complex perceptual vocabulary is the opposite of what Descartes thought. Descartes argued in the second Meditation on the First Philosophy that he could doubt his senses, but not that things seem to be so-and-so. He thought that our knowledge of objects and their properties is secondary to our knowledge of these subjective experiences. Yet we have seen that this is incorrect: mastery of a perceptual vocabulary (the use of verbs of perception and their cognates) presupposes antecedent mastery of an observational vocabulary of perceptibilia, i.e. the ability to name things and their properties and knowing how to describe objects.

\section{Explanations of Blindsight}

Descartes and his successors (e.g. Locke, Hume and James) held that it is the mind that perceives, for he conceived perceiving to be a form of thought. Moreover, he argued that we cannot perceive without being conscious of perceiving and of what one perceives. Animals do not in this sense perceive, since they are, according to Descartes, not conscious and do not have sensory experiences. Accordingly, animal perception is mechanical responsiveness to stimuli. It is not accompanied by consciousness of sensory experience, as it is in the case of humans.

One consequence of Descartes' redefinition of thought in terms of consciousness is that perception is in humans subdivided in two stages. During the first stage the brain receives 'sensory or unprocessed data' (called 'sensations' by Helmholtz and 'representations' by cognitive neuroscientists). These data are during the second stage 'combined' (or 'interpreted', 'synthesized') into conscious perceptions (also called 'meta-representations' or 'conscious experiences' by cognitive neuroscientists). We can become aware of these experiences because we have access to them, either by introspection, or by a 'self-monitoring system' in the brain. This conception of how perceptual consciousness arises was and still is used to explain neurological disorders. For example James (1950, vol. 1, pp. 41f) distinguished sensorial blindness from psychic blindness and explained the former as 'absolute insensibility to light' and the latter as the 'inability to recognize the meaning of the optical impressions'. We shall argue that the distinction between the two stages leads to misguided explanations of neurological disorders, and discuss blindsight as an example.

While investigating a patient (of whom his right occipital lobe surgically was removed), Weiskrantz, who coined the term 'blindsight', observed a dissociation between what he called 'reacting' and 'monitoring'. The first term refers to the performance of patients in forced choice tasks (showing that patients could respond to stimuli); the second to the commentary of patients on their own performances (they reported that they were not aware of what they saw). Monitoring is here used as a description of what the patient reports and, hence, is part of the description of a clinical 
syndrome. However, Weiskrantz also used the term 'monitoring' for explaining the observed dissociation: he hypothesized that there is a 'monitoring system' in the brain that is 'not part of the serial information-processing chain itself'. This system is an interior perceptual faculty, which is in the case of blindsight no longer capable of (consciously) monitoring the results of visual processing (as if it were an introspective faculty) because it is disconnected to the parts that process information. Hence like other cognitive neuroscientists, he postulated a neural structure (that receives information processed by other parts of the brain) upon which all conscious experience depends. According to Weiskrantz (1987, p. 317), the (neural) monitoring system 'creates conscious experience' to which the owner has privileged access.

Let us first elaborate the neurological explanation of blindsight. In mammals, there are two pathways involved in vision (Diamond and Hall 1969), the phylogenetically older collicular pathway and the newer geniculate-V1 pathway (V1 is the primary visual cortex). Patients with a complete lesion of V1 (e.g. as the result of a stroke) are clinically blind, though they still respond to moving stimuli without reporting that they perceive them (they do not consciously perceive moving stimuli). Since motion detection is the most consistent feature of blindsight (Leopold 2012), it raises the question of how we can explain it. The point to notice is that motion detection depends on the superior colliculus. This structure receives input from the eye and projects via the caudal pulvinar to the lateral-temporal cortex (Beltramo and Scanziani 2019; Kinoshita et al. 2019). This collicular pathway was probably in vertebrates the first one connecting the eye to the cortex. We know for example that the collicular pathway enables frogs to detect movement in their visual field (they respond to a fly crossing their visual field). Hence we can explain blindsight in terms of the combination of an intact collicular pathway and a distorted geniculate-V1 pathway.

Does this explanation exemplify the Cartesian distinction between mechanical response to stimuli by animals and conscious perception only in humans? The answer is no. Frogs lack a neocortex (they have a single visual system) and their responses to moving objects crossing their visual field are highly robust: their eyes do not follow the moving object, they do not attend to it, and so on (Lettvin et al. 1959; Krauzlis et al. 2018). Hence there is little reason to say that the concept of perceptual consciousness is applicable to them: they are not in receipt of knowledge since their attention is not caught and held by a moving object in their visual field (it is largely an innate response). However, the responses of for example nonhuman primates (they have, like us, two visual systems) are highly flexible, for they follow objects with their eyes, attend to what they see, and so forth. So we can say that they are in receipt of knowledge when they perceive something, although they cannot, like humans, express what they perceive in linguistic behaviour and, hence, cannot inform others about what they see. Unsurprisingly, there are good reasons to say that blindsight, as the result of a lesion of V1, can also occur in primates (see Leopold 2012).

We have seen that children acquire in addition to their discriminatory abilities the capacity to use a perceptual vocabulary. They do not only respond to what they see but also learn to express what they perceive with the aid of this vocabulary. Mutations or brain lesions due to trauma may affect both discriminatory capacities and the use of a perceptual vocabulary. For example individuals who are colour-blind (red-green colour blindness) as the result of a mutation cannot discriminate between green, red and grey. And because of that, they also cannot use our rules for the use of the concepts 'red' and 
'green' (they cannot use samples to explain the meaning of these words) and the associated perceptual vocabulary. That is unsurprising, since the capacity to use these rules evolves as an extension of our (innate) discriminatory capacities. The explanation of blindsight is similar to the one given for colour blindness: these patients are no longer capable of telling what they see, cannot attend to what they see, and so on and so forth. Yet what is of course interesting is that, although patients with the disorder are blind, they respond to moving objects though they are then not aware of what they then see. Is this data an argument in favour of the Cartesian distinction between reacting and monitoring? It is not, for there is no such thing as a form of inner perception to which the subject has privileged access. Blindsight does not exemplify a disconnection between unconscious information processing and an interior perceptual faculty (an introspector), as Weiskrantz and others believe, but exemplifies the disruption of the normal pattern of regularities of nonverbal and linguistic behaviour which underlies our use of perceptual verbs. Normally the indices of sight like behavioural responses, linguistic expressions and reports, or answers to questions converge. These convergences constitute the framework within which verbs of vision are used and taught. What characterizes blindsight is that under special experimental conditions only some of these criteria for seeing are satisfied (patients can respond to moving objects, and, presumably depending whether there is a complete lesion of V1 or not, can discriminate simple patterns, and so on), and some of the criteria for lack of vision (Bennett and Hacker 2003, pp. 393-396; Hyman 1991). The consequence of this lack of convergence is that we can neither say that the patients see nor that they cannot see objects. We are at loss to describe the dissociation between behavioural response and linguistic report and are therefore inclined to use paradoxical expressions such a 'blindsight' or 'unconscious awareness'. Thus neo-Aristotelians argue that blindsight exemplifies how as the result of a neurological disorder the capacity to use mental concepts like 'vision' crumbles.

The discussion of differences between Cartesian and neo-Aristotelian explanations of neurological disorders enables us to answer the question of how the neo-Aristotelian conception resolves Comte's challenge. The neo-Aristotelian answer is a conceptual resolution. Comte discusses introspection as if it were a form observing something with inner eyes, leading to the problem whether the mind can simultaneously perceive and observe itself perceiving. Yet we have seen that there is no such thing as observing oneself observe, for there are no inner eyes nor is there anything interesting to see. Introspection is not observing oneself perceiving; it is reflecting on what we see, feel, think or intend to do. That is a capacity that evolves when children become languageusers and acquire (what Aristotle called) a rational psuchē. For only a language-using creature which possesses the concepts of anger, depression, excitement or love, can realize or become conscious of the fact that he or she is angry, depressed, excited or in love. Humans can engage in forms of self-reflection when trying to determine, for example, the nature of their feelings (e.g. whether they really love someone). Such soul-searching inquiries require imagination and judgement, but no 'inner eye', for there is no inner eye and nothing to perceive. Thus we must not, as Comte, James and others did, confuse the capacity to say with the capacity to introspect or apperceive. Dehaene, Weiskrantz and others correctly noticed that humans can express and report their conscious experiences (what they perceive, and so on), but they mistakenly thought that these expressions and reports are grounded in introspection (somewhere 
located in a neural system). But introspection is not like observing something in the subjective realm; this is merely a misleading metaphor. Instead of asking the Cartesian question of how linguistic (first-person) expressions ('I see a rose'; 'I have a pain'; 'I think that ...') are grounded in private experiences (introspection), we should pose a different question: what are the conceptual preconditions for a human being to avow or report groundlessly how things are with him or her (see further Hacker 2019; Wittgenstein 1993).

\section{Conclusion}

Comte argued that the mind cannot simultaneously perceive, feel, or think and observe itself so doing. Dehaene responded to Comte's challenge by arguing that we have to reformulate his problem in terms of the brain. We have argued that both Comte's formulation and Dehaene's reformulation presuppose the misguided idea that introspection is a form of observation. It is, for conceptual reasons, misguided to argue that there is such a thing as introspecting objects of the world within us (while we can inspect the objects in the world around us). The analogy between introspection and inspection is only confusing: words do not get a meaning by attaching them to experiences (as if there are mental entities), for experiences are not entities of any kind. Moreover, there are no such things as inner eyes with which we can introspect or see putative mental entities; there are no fingers with which we can point to the content of experiences in the mental realm. Comte challenge and Dehaene's reformulation are rooted in a Cartesian misconception we first must abandon. If we have done that, then we can reformulate Comte's challenge in terms of the neo-Aristotelian conception. It becomes: how should we conceive of the development of the capacity of children to reflect on what they feel and perceive? We have already answered this question. Babies and infants have sensations (expressed in natural behaviours like facial expressions), respond to perceptual stimuli, and so on, but they cannot yet reflect on what they see and what they have felt and done, for reflective consciousness presupposes mastery of the use of a language. Hence the correct question Comte should have asked is: what are the preconditions for children to avow or report how things are with themselves? In terms of developmental science: how do children learn to say how things are with them?

We end with briefly discussing a mistake made by the grandfather of psychology James. In his response to Comte's challenge, James argued that, although infants can be in a mental state, being in a mental state is not sufficient for knowledge, for otherwise infants would be 'infallible psychologists'. James (1950, vol. 1, p. 89) correctly noticed that children must not only have sensations and emotions, learn things, and so forth, but must also be capable 'to report them and write about them, name them, classify and compare them and trace their relations to other things'. Yet he misguidedly added that 'as in the naming, classing, and knowing of things in general we are notoriously fallible, why not also here?' Like Descartes, Comte and others, James thought that there is no difference between introspection and observation of whatever kind, and added that both are fallible. However, since introspection is not like observing something, there is no such thing as making mistakes. When a child lies about what he or she has perceived or has done, he or she does not make a mistake for a lie is not a mistake: 
he or she is insincere. James, like Comte, confuses introspection and seeing and could therefore not clearly answer the question of how the one relates to the other.

Acknowledgments We thank a reviewer for his or her helpful comments on an earlier version of this article.

Open Access This article is licensed under a Creative Commons Attribution 4.0 International License, which permits use, sharing, adaptation, distribution and reproduction in any medium or format, as long as you give appropriate credit to the original author(s) and the source, provide a link to the Creative Commons licence, and indicate if changes were made. The images or other third party material in this article are included in the article's Creative Commons licence, unless indicated otherwise in a credit line to the material. If material is not included in the article's Creative Commons licence and your intended use is not permitted by statutory regulation or exceeds the permitted use, you will need to obtain permission directly from the copyright holder. To view a copy of this licence, visit http://creativecommons.org/licenses/by/4.0/.

\section{References}

Austin, J.L. (1962) Sense and Sensibilia. Reconstructed from the manuscript notes by G. J Warnock. Oxford: Oxford University Press.

Baker, G. P., \& Hacker, P. M. S. (2005). Wittgenstein: Meaning and understanding. Oxford: Basil Blackwell Second edition, revised by P.M.S. Hacker; first edition 1983.

Beltramo, R., \& Scanziani, M. (2019). A collicular visual cortex: neocortical space for an ancient midbrain visual structure. Science, 363, 64-69.

Bennett, M. R., \& Hacker, P. M. S. (2003). Philosophical foundations of neuroscience. Oxford: Blackwell Publishing.

Ben-Yami, H. (2015). Descartes' philosophical revolution: A reassessment. Basingstoke: Palgrave Macmillan.

Carnap, R. (1961). Der Logische Aufbau der Welt. Hamburg: Meiner.

Cohen, R. S., \& Elkana, Y. (Eds.). (1977). Helmholtz's Epistemological Writings, trs. M.F. Lowe. Dordrecht: Reidel.

Darwin, C. (1968 [1859]). On the origin of species by means of natural selection. Hammondsworth: Penguin Books.

Dehaene, S. (2014). Consciousness and the brain; deciphering how the brain codes our thoughts. New York: Penguin books.

Dennett, D. (1993). Consciousness explained. Harmondsworth: Penguin.

Diamond, I. T., \& Hall, W. C. (1969). Evolution of Neocortex. Science, 164(3877), 251-262.

Feigl, H. (1949). Logical Empiricism. In H. Feigl \& W. Sellars (Eds.), Readings in philosophical analysis (pp. 3-26). New York: Appleton-Century-Croft.

Hacker, P. M. S. (1995). Helmholtz's theory of perception: An investigation into its conceptual framework. International Studies in the Philosophy of Science, 9, 199-214.

Hacker, P. M. S. (2007). Human nature; the Categorial framework. Oxford: Basil Blackwell.

Hacker, P. M. S. (2019). Wittgenstein: Meaning and Mind. Second, revised edition, first edition 1990. Chichester: Wiley-Blackwell.

Hadders-Algra, M. (2018a). Early human brain development: Starring the subplate. Neuroscience and Biobehavioral Reviews., 92, 276-290.

Hadders-Algra, M. (2018b). Early motor development: From variation to the ability to vary and adapt. Neuroscience and Biobehavioral Reviews., 90, 411-427.

Hyman, J. (1991). Visual experience and blindsight. In J. Hyman (Ed.), Investigating Psychology; Sciences of the Mind after Wittgenstein (pp. 166-200). London: Routledge.

James, W. (1950 [1890]). The Principles of Psychology, two volumes. New York: Dover.

Kenny, A. (1988) Cosmological explanation and understanding. In: Perspectives on Human Conduct (L. Herzberg \& J. Pietarinen, eds.), 72-87. Leiden: Brill.

Kinoshita, M., Kato, R., Isa, K., Kobayasi, K., Kobayasi, K., Onoe, H., \& Isa, T. (2019). Dissecting the circuit for blindsight to reveal the critical role of pulvinar and superior colliculus. Nature. Communications, 10, 135, (2019). https://doi.org/10.1038/s41467-018-08058-0. 
Kirschner, M., \& Gerhart, J. C. (2005). The plausibility of life; resolving Darwin's dilemma. New Haven: Yale University Press.

Kostović, I., Sedmak, G., \& Judaš, M. (2019). Neural histology and neurogenesis of the human fetal and infant brain. Neuroimage, 188, 743-773.

Krauzlis, R. J., Bogadhi, A. R., Herman, J. P., \& Bollimunta, A. (2018). Selective attention without a neocortex. Cortex, 102, 161-175.

Leopold, D. A. (2012). Primary Visual Cortex: Awareness and Blindsight. Annual Review of Neuroscience, 35, 91-109.

Lettvin, J. Y., Maturana, H. R., McCulloch, W. S., \& Pitts, W. H. (1959). What the frog's eye tells the frog's brain. Proceedings of the IRE., 47, 1940-1959.

Mill, J. S. (1961 [1865]). August Comte and positivism (Fourth ed.). London: Kegan Paul.

Nachev, P., \& Hacker, P. M. S. (2010). Covert cognition in the persistent state. Progress in Neurobiology, 91 , $68-76$.

Ryle, G. (2009). Sensation. In Collected Essays 1929-1968; Collected Papers Volume 2, chapter 26. London: Routledge.

Shultz, S., Klin, A., \& Jones, W. (2018). Neonatal transitions in social behavior and their implications for autism. Trends in Cognitive Science., 22, 452-469.

Tononi, G. (2005). Consciousness, information integration, and the brain. Progress in Brain Research., 150 chapter 9.

Warren, R. M., \& Warren, R. P. (Eds.). (1968). Helmholtz on perception; its physiology and development. New York: John Wiley \& sons.

Weiskrantz, L. (1987). Neuropsychology and the nature of consciousness. In C. Blakemore \& S. Greenfield (Eds.), Mindwaves (pp. 307-320). Oxford: Blackwell.

Wittgenstein, L. (1993). The language of sense data and private experience (notes taken by R. Rhees of Wittgenstein's lectures, 1936), pp. 290-367. In J. Klagge \& A. Nordmann (Eds.), Ludwig Wittgenstein; philosophical occasions, 1912-1951. Hackett: Indianapolis.

Publisher's Note Springer Nature remains neutral with regard to jurisdictional claims in published maps and institutional affiliations. 